\title{
Factors associated with high heterogeneity of malaria at fine spatial scale in the Western Kenyan highlands
}

\author{
Amrish Y. Baidjoe ${ }^{1,2}$, Jennifer Stevenson ${ }^{3,4}$, Philip Knight ${ }^{5}$, William Stone ${ }^{1}$, Gillian Stresman ${ }^{3}$, Victor Osoti , \\ Euniah Makori ${ }^{6}$, Chrispin Owaga ${ }^{6}$, Wycliffe Odongo ${ }^{6}$, Pauline China ${ }^{6}$, Shehu Shagari ${ }^{6}$, Simon Kariuki ${ }^{6}$, \\ Chris Drakeley ${ }^{3}$, Jonathan Cox ${ }^{3}$ and Teun Bousema ${ }^{1,3^{*}}$
}

\begin{abstract}
Background: The East African highlands are fringe regions between stable and unstable malaria transmission. What factors contribute to the heterogeneity of malaria exposure on different spatial scales within larger foci has not been extensively studied. In a comprehensive, community-based cross-sectional survey an attempt was made to identify factors that drive the macro- and micro epidemiology of malaria in a fringe region using parasitological and serological outcomes.

Methods: A large cross-sectional survey including 17,503 individuals was conducted across all age groups in a $100 \mathrm{~km}^{2}$ area in the Western Kenyan highlands of Rachuonyo South district. Households were geo-located and prevalence of malaria parasites and malaria-specific antibodies were determined by PCR and ELISA. Household and individual risk-factors were recorded. Geographical characteristics of the study area were digitally derived using highresolution satellite images.

Results: Malaria antibody prevalence strongly related to altitude (1350-1600 m, p < 0.001). A strong negative association with increasing altitude and PCR parasite prevalence was found. Parasite carriage was detected at all altitudes and in all age groups; $93.2 \%$ (2481/2663) of malaria infections were apparently asymptomatic. Malaria parasite prevalence was associated with age, bed net use, house construction features, altitude and topographical wetness index. Antibody prevalence was associated with all these factors and distance to the nearest water body.

Conclusion: Altitude was a major driver of malaria transmission in this study area, even across narrow altitude bands. The large proportion of asymptomatic parasite carriers at all altitudes and the age-dependent acquisition of malaria antibodies indicate stable malaria transmission; the strong correlation between current parasite carriage and serological markers of malaria exposure indicate temporal stability of spatially heterogeneous transmission.
\end{abstract}

Keywords: Malaria, Plasmodium falciparum, Hotspots, Heterogeneity, Transmission, Elimination, Risk-factors, Serology, Polymerase chain reaction

\section{Background}

Infectious disease transmission often displays heterogeneity of transmission in space and time [1]. Malaria forms no exception to this and in the last decade, considerable

\footnotetext{
*Correspondence: teun.bousema@lshtm.ac.uk

${ }^{3}$ Department of Infectious and Tropical Diseases, London School of Hygiene and Tropical Medicine, Keppel Street, WC1E 7HT London, UK Full list of author information is available at the end of the article
}

efforts have been made to improve estimates on the global and local burden of malaria transmission $[2,3,4]$. At a global scale, Plasmodium falciparum transmission is driven by temperature and aridity that limit the distribution and competence of Anopheles vectors [5]. However, at a micro-epidemiological scale in endemic areas, numerous factors influence malaria transmission dynamics including distance to the nearest mosquito breeding site $[6-12]$ and house construction features $[6,8,9,13$, 
14]. Individual malaria risk may also be associated with human genetic factors $[7,8,15]$ or with behavioural factors $[6-8,13]$ including those relating to occupation [16] and travel [17]. Variations in these factors over a small area can result in spatially heterogeneous transmission, resulting in foci or hotspots of malaria infection $[2,18]$. Targeting hotspots may be a highly efficacious approach for malaria control $[1,19]$; the operational feasibility of such targeted interventions depends on the stability of malaria hotspots in space and time $[2,20]$ and the ability to readily detect them.

In Africa, highland fringe areas have traditionally been associated with unstable malaria transmission, epidemics and unpredictable disease patterns [21, 22]. Over recent decades, however, it appears that this picture has been changing [23] with studies describing instances of relatively stable malaria transmission in the Kenyan highlands [24, 25], characterized by age-dependent acquisition of anti-malarial immunity $[24,26]$ and a substantial reservoir of asymptomatic malaria infections [27]. These studies were based on passively detected malaria cases $[24,25]$ and active surveillance in children [26, 27]; a more comprehensive, community-based, assessment of parasitological and serological outcomes in all age groups is needed to establish the macro- and micro-epidemiology of $P$. falciparum and to identify factors associated with exposure and infection so that more targeted and specific interventions can be locally deployed.

\section{Methods}

\section{Study site and sampling}

This study was conducted in highland fringe localities (1350-1600 m altitude) in Rachuonyo South District, western Kenya (Fig. 1). The main malaria vectors in the area are Anopheles funestus and Anopheles gambiae sensu lato (s.l.) [28]. Malaria transmission is seasonal, with two peaks in malaria cases reflecting the bimodal rainfall pattern, with the heaviest rainfall typically occurring between March and June and a smaller peak between October and November each year. The study procedures have been described in detail elsewhere as part of an online clinical trial protocol [29]. Briefly, a $5 \times 20 \mathrm{~km}\left(100 \mathrm{~km}^{2}\right)$ area was selected and divided into 400 cells of $500 \times 500 \mathrm{~m}$ that were further subdivided in four sub-cells of $250 \times 250 \mathrm{~m}$. All structures in the area were geo-located manually in ArcGIS [ArcGIS 9.2; Environmental Systems Research Institute, Redlands, CA, USA] using contemporaneous high-resolution satellite data [Quickbird; DigitalGlobe Services, Inc., Denver, CO, USA]. Where possible, a maximum of 16 compounds were chosen from each $500 \times 500 \mathrm{~m}$ cell. The aim was to obtain measurements from $\geq 50$ individuals per $500 \times 500 \mathrm{~m}$ and sampling of individuals was guided by

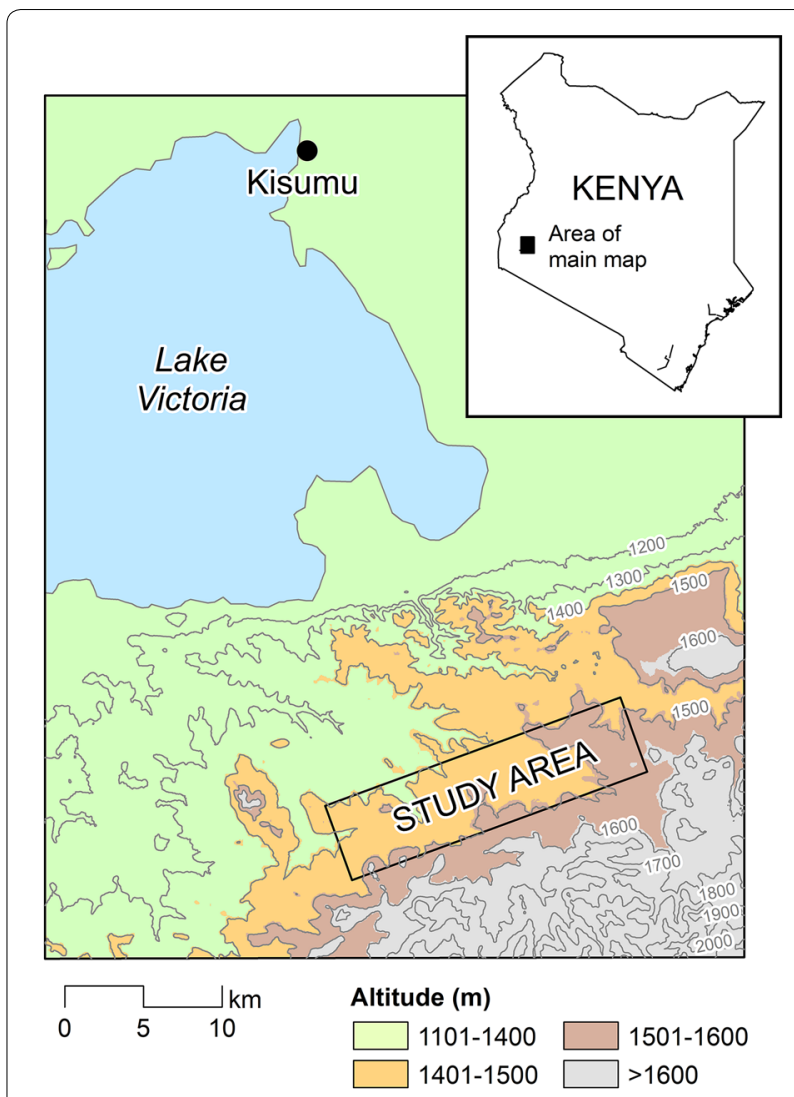

Fig. 1 The study area in Western Kenya. The study area comprised a $5 \times 20$ km rectangle in Rachuonyo South District, Nyanza Province

pre-defined age strata ( $\leq 5$ years; $6-10$ years; $11-15$ years; 16-25 years and $>25$ years) to maximize the discriminative power of serological markers of exposure [30]. To ensure maximum geographical coverage, at least one compound was selected from each $250 \times 250 \mathrm{~m}$ sub-cell while the number of compounds selected from each of the $250 \times 250 \mathrm{~m}$ sub-cells was weighted by the density of structures in each sub-cell.

The survey was carried out in 2011, during what is considered to be the main malaria transmission season, between June and July. After initial consent during enumeration, participating compounds were visited and the name, gender, age, residency and travel history, use of insecticide-treated nets (ITNs), indoor residual spraying (IRS) in the past 12 months and sleeping times of each compound member were recorded. All compounds where at least one adult ( $>20$ years) and one child ( $<15$ years) were permanent residents (defined as sleeping regularly in the structure) qualified for enrolment during the survey. The axillary temperature of each compound member was measured by digital thermometer. For all febrile individuals a rapid diagnostic test [RDT; Paracheck ${ }^{\circledR}$, Orchid BiomedicalSystems, Goa, 
India] detecting $P$. falciparum-specific histidine rich protein-2 was performed. A single finger prick sample was taken for haemoglobin $(\mathrm{Hb})$ measurement using a HemoCue photometer [HemoCue 201+, Angelholm, Sweden] and three droplets of blood transferred onto a filter paper [3MM Whatman, Maidstone, UK] for serum and DNA [31]. All individuals with an $\mathrm{Hb} \leq 11 \mathrm{~g} / \mathrm{dL}$ were given haematenics; individuals with an $\mathrm{Hb} \leq 6 \mathrm{~g} / \mathrm{dL}$ were accompanied to a nearby health centre for further care. Febrile individuals who were parasitaemic by RDT were given artemether-lumefantrine [AL, Coartem ${ }^{\circledR}$, Novartis, Switzerland]; women of child bearing age who were RDT positive were assessed for pregnancy and offered a pregnancy test if deemed appropriate. Febrile children below 6 months of age and pregnant women with malaria were referred to the nearest health facility for full assessment and treatment.

\section{PCR and serology}

A combined extraction of DNA and elution of antibodies was performed on the samples collected, as described elsewhere [31]. Antibodies against $P$. falciparum apical membrane antigen 1 (AMA-1) and merozoite surface protein $1_{19}\left(\right.$ MSP-1 $\left.1_{19}\right)$ were measured in all samples by ELISA [32, 33]. Parasites were detected by nested PCR targeting the 18S rRNA gene [31, 34]. For logistical reasons, PCR was performed on a subset of all available samples $(12,912 / 16,381)$.

\section{Geographical information}

Altitude data for study compounds were derived from a high-resolution digital elevation model (DEM; ASTER GDEM). These DEM data were also used to derive a topographic wetness index (TWI) using the method of Cohen et al. [35]. Aggregated TWI estimates were derived for a $500 \mathrm{~m}$ circular window around each participating compound. Locations of rivers and streams were initially estimated using topographic modelling of DEM data and were later refined manually using Quickbird satellite data. The number of digitised structures within a $500 \mathrm{~m}$ circular window of each compound was used as a proxy for population density.

\section{Statistical analysis}

Broad patterns of transmission intensity were described by fitting age-seroprevalence curves $[32,36]$ to samples collected from populations residing at different altitude bands 1350-1449 m, 1450-1499 m, 1500-1549 m and $1550-1641 \mathrm{~m}$ and quantifying parasite prevalence and antibody prevalence in $10 \mathrm{~m}$ altitude bands. For quantifying transmission intensity at a finer geographical scale, two individual level measures of transmission intensity were used: (1) combined antibody prevalence, i.e. seropositivity for AMA-1 and/or MSP$1_{19}$; and (2) PCR-detected parasite prevalence. Correlations between both metrics were determined using a Chi square test and hypothesis testing with significance determined where $\mathrm{p}<0.05$ and odds ratios (OR) and corresponding $95 \%$ confidence intervals were calculated. Potential factors associated with antibody prevalence or parasite prevalence were explored using multivariate logistic regression models accounting for correlations between observations from the same compound. In these models, an equal correlation model (exchangeable) was used to specify the within-household correlation structure. All univariate analyses were adjusted for clustering of observations from the same household and age but no other factors. Adjustment for age was performed because this was a very important determinant of both parasite prevalence and antibody prevalence. For multivariate models a forward selection method was used, using a $\mathrm{p}$ value of 0.05 to retain variables in the model. All analyses were performed using Stata [v. 13, StataCorp].

\section{Ethical considerations}

This study was approved by the ethical committees of the London School of Hygiene and Tropical Medicine (LSHTM 5721) and the Kenya Medical Research Institute (SSC 1802 \& SSC2163). Approval was sought from district medical officers, local chiefs and communities. Individual informed consent was sought from all participants or guardians of those less than 18 years old by signature or a thumbprint accompanied with the signature of an independent witness. Assent was also sought from children above 13 years of age. As defined in the Kenya national guidelines, participants below 18 years of age who were pregnant, married, or a parent were considered "mature minors" and consented for themselves.

\section{Results}

Characteristics of the study population

In total 17,503 individuals were sampled, coming from 3213 compounds across a $100 \mathrm{~km}^{2}$ study area. The majority of individuals resided within a narrow altitude band of $1400-1550 \mathrm{~m}(92.5 \% ; 16,167 / 17,478)$. The median number of individuals per compound was 5 (interquartile range $3-7$, range $1-29$ ). As reported recently, PCR detected parasite prevalence was $21.2 \%(738 / 3476)$ in children $\leq 5$ years of age, $26.1 \%(609 / 2337)$ in children aged $6-10$ years, $24.8 \%(462 / 1403)$ in children aged 11-15 years, $19.2 \%(374 / 1574)$ in individuals aged $16-25$ years and $14.6 \%(480 / 3286)$ in individuals aged $>25$ years [37]. 


\section{Altitude and malaria risk}

The proportions of individuals with fever, clinical malaria (a positive RDT in combination with temperature $\geq 37.5{ }^{\circ} \mathrm{C}$ ), parasites detected by PCR, malaria-specific antibody responses (Fig. 2) and anaemia ( $\mathrm{Hb}<11 \mathrm{~g} / \mathrm{gL})$ were all negatively associated with increasing altitude (Table 1; p $<0.001$ for all comparisons). The median age of individuals diagnosed with clinical malaria was 6 years (interquartile range 3-10 years), although $12.5 \%$ $(37 / 295)$ individuals with clinical malaria were $>15$ years of age (range $0-46$ years); $93.2 \%$ (2481/2663) of PCRdetected malaria infections were sub-clinical. The mean age of individuals with clinical malaria was not associated with altitude $(\mathrm{p}=0.40)$. When altitude was categorized in bins of $10 \mathrm{~m}$, there was a strong negative association between altitude and PCR parasite prevalence (Fig. 3a; $\mathrm{r}=0.92, \mathrm{p}<0.0001)$ and malaria antibody prevalence $(\mathrm{r}=0.92, \mathrm{p}<0.0001)$. Age-seroprevalence curves were fitted for antibody responses to MSP- $1_{19}$ and/or AMA-1 for the four altitude bands and indicated a clear gradual decline of the seroconversion rate with increasing altitude (Fig. 3b). There are no apparent observed 'steps' in age-seroprevalence curves that can indicate changes in exposure due to intervention and/or age-associated behavioral changes patterns such as travel to malaria endemic regions outside the area of residence [38].
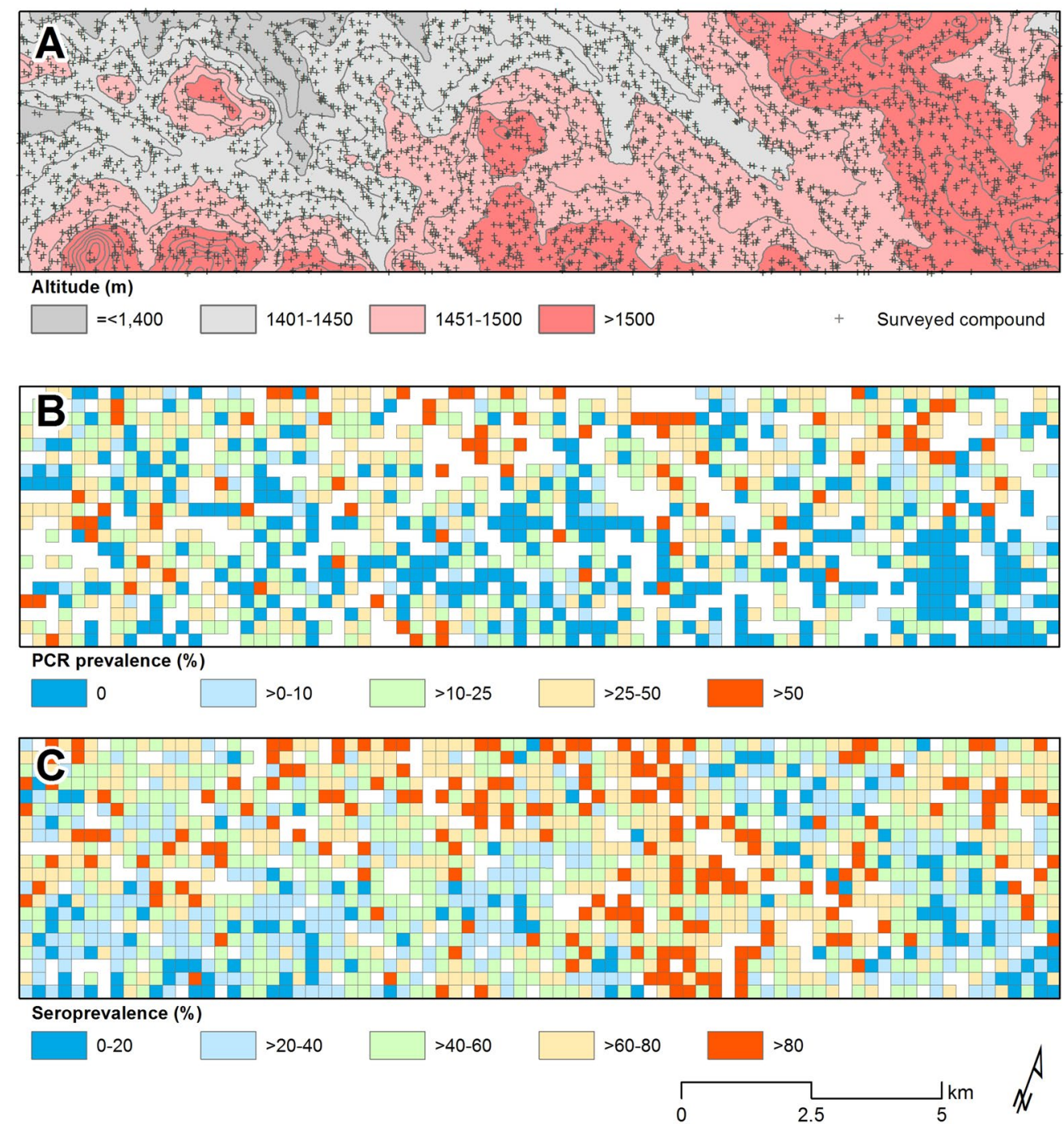

Fig. 2 Maps representing altitude, spatial variation of nPCR and antibody prevalence in the study area Western Kenyan highlands Rachuonyo South District, Nyanza Province. A Detailed overview of the altitude in the study area. B Average nPCR prevalence in $250 \times 250 \mathrm{~m}$ zones. C Average combined seroprevalence (for AMA-1 or MSP-1 ${ }_{19}$ ) in $250 \times 250 \mathrm{~m}$ zones 
Table 1 Characteristics of participants in the cross-sectional survey

\begin{tabular}{|c|c|c|c|c|c|}
\hline & $1350-1449 \mathrm{~m}$ & $1450-1499 \mathrm{~m}$ & $1500-1549 \mathrm{~m}$ & $1550-1650 \mathrm{~m}$ & Total \\
\hline $\begin{array}{l}\text { Number of participants (number of com- } \\
\text { pounds) }\end{array}$ & $5424(1108)$ & $6363(1235)$ & $4579(816)$ & $839(140)$ & $17,503(3213)$ \\
\hline \multicolumn{6}{|l|}{ Age, \% (n/N) (years) } \\
\hline$<5$ & $26.4(1429 / 5424)$ & $27.0(1791 / 6636)$ & $27.1(1239 / 4579)$ & $27.7(232 / 839)$ & $26.9(4701 / 17,503)$ \\
\hline $6-10$ & $18.9(1024 / 5424)$ & $18.1(1202 / 6636)$ & $18.0(822 / 4579)$ & $19.4(163 / 839)$ & $18.4(3215 / 17,503)$ \\
\hline $11-15$ & $15.2(823 / 5424)$ & $13.9(923 / 6636)$ & $15.0(685 / 4579)$ & $14.3(120 / 839)$ & $14.6(2552 / 17,503)$ \\
\hline $16-25$ & $13.7(744 / 5424)$ & $15.3(1018 / 6636)$ & $14.8(677 / 4579)$ & $16.5(138 / 839)$ & $14.7(2579 / 17,503)$ \\
\hline$>26$ & $25.9(1404 / 5424)$ & $25.7(1702 / 6636)$ & $25.3(1156 / 4579)$ & $22.2(186 / 839)$ & $25.5(4456 / 17,503)$ \\
\hline Fever, \% temperature $>37.5^{\circ} \mathrm{C}, \%(\mathrm{n} / \mathrm{N})$ & $4.0(216 / 5423)$ & $3.1(204 / 6631)$ & $2.5(116 / 4575)$ & $1.3(11 / 839)$ & $3.1(547 / 17,468)$ \\
\hline Clinical malaria, \% $(\mathrm{n} / \mathrm{N})^{\mathrm{a}}$ & $2.3(126 / 5423)$ & $1.8(120 / 6631)$ & $1.1(48 / 4575)$ & $0.12(1 / 839)$ & $1.7(295 / 17,468)$ \\
\hline Parasite prevalence, \% PCR positive (n/N) & $27.2(1111 / 4083)$ & $19.6(900 / 4599)$ & $16.7(592 / 3548)$ & $8.1(54 / 664)$ & $20.6(2663 / 12,912)$ \\
\hline Antibody prevalence, $\%$ positive $(n / N)^{b}$ & $62.6(3108 / 4967)$ & $58.0(3623 / 6252)$ & $48.3(2104 / 4361)$ & $31.7(246 / 777)$ & $55.5(9092 / 16,381)$ \\
\hline \multicolumn{6}{|l|}{ Anaemia, \% (n/N) } \\
\hline Severe $(<6 \mathrm{~g} / \mathrm{dL})$ & $0.6(30 / 5282)$ & $0.7(46 / 6391)$ & $0.4(19 / 4366)$ & $0.2(2 / 818)$ & $0.6(97 / 16,878)$ \\
\hline Moderate $(<8 \mathrm{~g} / \mathrm{dL})$ & $3.1(163 / 5282)$ & $3.4(214 / 6391)$ & $2.6(112 / 4336)$ & $2.0(16 / 818)$ & $3.0(505 / 16,878)$ \\
\hline Mild (<11 g/dL) & $26.0(1374 / 5282)$ & $23.0(1472 / 6391)$ & $21.5(938 / 4336)$ & $20.2(165 / 818)$ & $23.4(3954 / 16,878)$ \\
\hline
\end{tabular}

a Clinical malaria is defined as fever with a positive RDT with measured temperature $>37.5^{\circ} \mathrm{C}$

b Prevalence of antibodies against $P$. falciparum MSP-1 ${ }_{19}$ and/or AMA-1

\section{Micro-epidemiological patterns in malaria transmission intensity}

There was considerable inter-compound variation in antibody prevalence and PCR parasite prevalence. In some compounds no members were antibody positive $(6.6 \%$ of all compounds with $\geq$ three sampled inhabitants, $178 / 2709)$ or PCR parasite positive $(49.6 \%, 1239 / 2496)$ while for other compounds $\geq 80 \%$ of all compound members were antibody $(24.1 \%, 652 / 2709)$ or parasite positive $(5.1 \%, 126 / 2496)$. Malaria antibody prevalence and parasite prevalence were strongly correlated at an individual level (OR 1.94, 95 \% confidence interval 1.77-2.13, $\mathrm{p}<0.001$ ) [37]. This association was apparent for all age groups but was strongest for children below 6-10 years of age (OR 3.16, 95 \% CI 2.58-3.86, p < 0.001) and weakest for adults above 25 years of age (OR 1.45, $95 \% \mathrm{CI}$ $1.15-1.83, \mathrm{p}=0.002$ ).

In univariate analysis, individual-level parasite prevalence and antibody prevalence was associated with age. When adjusting for age, the following factors were associated with parasite prevalence and antibody prevalence: the presence of eaves in the sleeping room, reported bed net use, construction of the sleeping room walls with mud, distance to water, altitude, the proportion of parasite positive individuals within a $500 \mathrm{~m}$ radius of the compound and the proportion of malaria antibody positive individuals within a $500 \mathrm{~m}$ radius of the compound (Table 2). In a multivariate model that was constructed using forward selection of variables, nPCR parasite prevalence was negatively associated with bed net use, altitude and maximum TWI, and positively associated with mud walls, the presence of open eaves (Table 2). Similarly, malaria antibody prevalence was negatively associated with bed net use, distance to water and altitude, and positively associated with the presence of open eaves and minimum TWI (Table 2). Reported travelling in the previous 3 months was not associated with individual-level malaria risk. At all altitudes, including the highest altitude band with the lowest level of infection $[8.1 \%(54 / 664)]$, there were compounds where $\geq 80 \%$ of inhabitants were parasite positive. The proportion of compounds with parasite prevalence $\geq 80 \%$ was $7.6 \%(68 / 896)$ at $1350-1449 \mathrm{~m}, 5.4 \%(56 / 1041)$ at $1450-1499 \mathrm{~m}, 4.8 \%(35 / 733)$ at $1500-1549 \mathrm{~m}$ and $2.3 \%$ $(3 / 128)$ at $>1550 \mathrm{~m}$ (test for trend, $\mathrm{p}=0.002)$. High-risk compounds were characterized by mud walls of sleeping structures (OR 1.94, 95 \% CI 1.00-3.79, p = 0.05), a higher PCR parasite prevalence in the surrounding community (OR 1.07, $95 \%$ CI 1.05-1.09, p < 0.001) and a higher minimum TWI (OR 2.60, 95 \% CI 1.37-4.95, $\mathrm{p}=0.004)$.

\section{Discussion}

This study, conducted in the Kenyan highlands, shows the occurrence of ongoing stable malaria transmission across an altitudinal range of 1350-1600 m, characterized by marked spatial heterogeneity. The age-dependent acquisition of malaria antibodies, strong correlation antibody prevalence and current parasite prevalence, along with the considerable asymptomatic reservoir of $P$. falciparum 

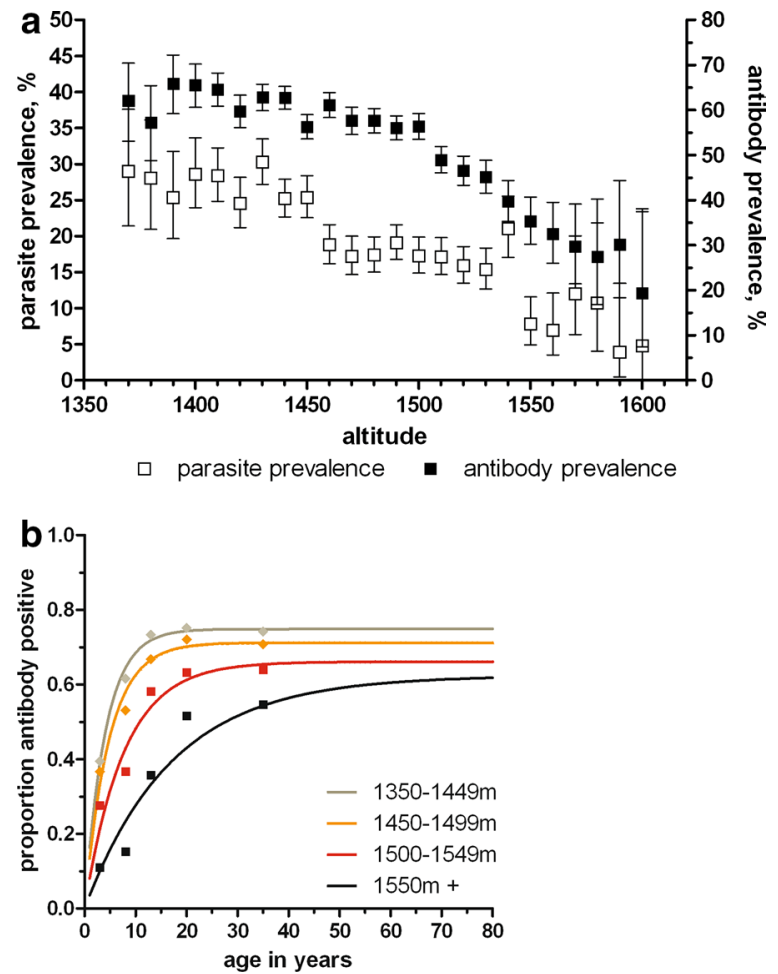

Fig. 3 Parasite prevalence and antibody responses in relation to altitude. a Presents parasite prevalence by PCR (open squares) and malaria-specific antibody prevalence (MSP-1 19 and/or AMA-1 antibodies detected by ELISA) showed a strong negative association with altitude ( $r=0.92, p<0.0001$ for both associations). b Presents the age-dependent antibody acquisition at different altitudes. Lines show the fitted association between age and antibody positivity for individuals residing at 1350-1449 $\mathrm{m}$ (grey line, $\mathrm{n}=4967), 1450-1499 \mathrm{~m}$ (orange line, $n=6252$ ), 1500-1549 $m$ (red line, $n=4361$ ) and 1550 meters and above (black line, $n=777$ ). Symbols indicate parasite prevalence estimates for children below 5 years of age, $6-10$ years, 11-15 years, $16-25$ years and $>26$ years. Symbols are plotted at the median age for the different categories; for the highest age category parasite prevalence is plotted at 35 years

infections in all age groups, suggests that malaria transmission is relatively stable in the study setting.

Much of the highlands of East Africa represent fringe regions between stable and unstable malaria transmission; seasonal and spatial patterns in malaria transmission are affected to some degree by annual variations in rainfall but primarily by ambient temperature [39]. The notion that malaria is largely absent in areas higher than $1500 \mathrm{~m}$ [40] has been challenged by findings of a large asymptomatic reservoir of malaria infections at altitudes [27] and an age-dependent acquisition of clinical immunity to malaria infections in highland communities [24]. In this study area area at $1350-1600 \mathrm{~m}$ above sea level, the special epidemiology of malaria infections was determined and markedly heterogeneous malaria transmission was observed. This is commonly observed in areas of low endemicity $[2,20,25]$ and heterogeneity in clinical malaria cases has previously been reported in the Kenyan highlands [25]. This study adds detail to previous findings by describing the fine-scale spatial distribution of asymptomatic parasite carriage and immunological evidence of previous malaria exposure in a highland area. PCR-detectable P. falciparum infections were very common in this highland setting, apparently asymptomatic and negatively correlated with altitude. Parasite prevalence by PCR was $27.2 \%$ in the population residing at $1350-1449 \mathrm{~m}, 19.6 \%$ at $1450-1499 \mathrm{~m}$, $16.7 \%$ at $1450-1549 \mathrm{~m}$ and $8.1 \%$ at $1550-1650 \mathrm{~m}$. Using an equation model fitted to 86 surveys that determined parasite prevalence by microscopy and PCR [41], the corresponding parasite prevalence could be estimated by microscopy at $9.7 \%(95 \%$ CI 8.3-11.2) at $1350-1449 \mathrm{~m}$, $6.1 \%(95 \%$ CI $5.1-7.3)$ at $1450-1499$ m, $5.0 \%$ (95 \% CI $4.1-6.1)$ at $1450-1549 \mathrm{~m}$ and $2.0 \%$ (95 \% CI 1.3-3.0\%) at $1550-1650 \mathrm{~m}$. Only a small fraction of these $P$. falciparum infections resulted in fever at the time of sampling and apparently asymptomatic parasite carriage was prevalent at all altitudes [27] and in all age-groups [41]. Recently, a manuscript summarized the evidence on the clinical consequences of chronic low density infections, arguing that many infections are incorrectly classified as asymptomatic and have considerable health consequences in terms of anaemia, chronic inflammation, school performance and bacterial infections [42]. Since the cross-sectional design of this study does not allow to determine whether the nPCR detected infections had clinical implications for the study population, it cannot be concluded with certainty whether the detected infections were indeed asymptomatic. However, concurrent clinical symptoms were reported by a small minority of the examined population and infections were probably chronic in nature. Although individuals with limited previous exposure may harbor low density infections [41], the high prevalence of apparently asymptomatic parasite carriage, absence of travelling as obvious risk factor for malaria and the gradual age- and altitude-dependent acquisition of antibody responses to $P$. falciparum antigens at different altitudes suggests stable local malaria transmission in the area.

Whilst travel, a known risk factor for malaria in highland areas [43, 44], was not significantly associated with individual risk of malaria infection or antibodies, several household factors such as the presence of open eaves and mud walls $[6,9]$ were statistically significant predictors of malaria risk. This suggests that relatively simple household improvements may decrease malaria risk $[45,46]$ in a region where the perceived and measured indoor exposure to malaria vectors is low [28]. Altitude, distance to 
Table 2 Factors associated with malaria parasite prevalence or antibody prevalence

\begin{tabular}{|c|c|c|c|c|}
\hline & \multicolumn{2}{|c|}{ Parasite prevalence } & \multicolumn{2}{|c|}{ Antibody prevalence } \\
\hline & $\mathrm{OR}^{\mathrm{a}}$ & Adjusted OR $(95 \% \mathrm{Cl})^{\mathrm{a}}$ & $\mathrm{OR}^{\mathrm{a}}$ & Adjusted OR $(95 \% \mathrm{Cl})^{\mathrm{a}}$ \\
\hline \multicolumn{5}{|l|}{ Individual characteristics } \\
\hline \multicolumn{5}{|l|}{ Age (years) } \\
\hline$\leq 5$ & 1 (reference) & 1 (reference) & 1 (reference) & 1 (reference) \\
\hline $6-10$ & $1.27(1.13-1.42)$ & $1.26(1.10-1.46)$ & $1.88(1.71-2.06)$ & $2.35(2.10-2.63)$ \\
\hline $11-15$ & $1.22(1.07-1.39)$ & $1.25(1.08-1.47)$ & $3.51(3.17-3.89)$ & $4.70(4.15-5.33)$ \\
\hline $16-25$ & $0.92(0.81-1.04)$ & $0.89(0.76-1.04)$ & $4.57(4.13-5.07)$ & $6.57(5.79-7.46)$ \\
\hline$\geq 26$ & $0.64(0.57-0.73)$ & $0.61(0.53-0.71)$ & $4.33(3.97-4.72)$ & $6.05(5.43-6.73)$ \\
\hline Bed net use & $0.79(0.71-0.88)$ & $0.82(0.72-0.93)$ & $0.85(0.79-0.93)$ & $0.89(0.81-0.98)$ \\
\hline \multicolumn{5}{|l|}{ House structure } \\
\hline Mud wall & $1.46(1.25-1.71)$ & $1.26(1.05-1.50)$ & $1.14(1.03-1.27)$ & \\
\hline Open eaves & $1.25(1.10-1.41)$ & $1.16(1.01-1.34)$ & $1.28(1.17-1.39)$ & $1.33(1.21-1.46)$ \\
\hline \multicolumn{5}{|l|}{ Environment } \\
\hline \multicolumn{5}{|l|}{ Distance to water } \\
\hline$<250 \mathrm{~m}$ & 1 (reference) & & 1 (reference) & 1 (reference) \\
\hline $250-500 \mathrm{~m}$ & $1.04(0.89-1.22)$ & & $0.97(0.87-1.09)$ & $1.04(0.92-1.19)$ \\
\hline $500-999 \mathrm{~m}$ & $0.83(0.71-0.96)$ & & $0.66(0.59-0.74)$ & $0.91(0.80-1.03)$ \\
\hline $1000 \mathrm{~m}+$ & $0.78(0.62-0.98)$ & & $0.44(0.38-0.52)$ & $0.81(0.67-0.97)$ \\
\hline \multicolumn{5}{|l|}{ Altitude (m) } \\
\hline $1350-1449$ & 1 (reference) & 1 (reference) & 1 (reference) & 1 (reference) \\
\hline $1450-1499$ & $0.63(0.55-0.72)$ & $0.84(0.72-0.98)$ & $0.83(0.75-0.91)$ & $0.90(0.81-1.01)$ \\
\hline $1500-1549$ & $0.52(0.45-0.61)$ & $0.68(0.56-0.81)$ & $0.57(0.51-0.64)$ & $0.79(0.69-0.89)$ \\
\hline $1550-1650$ & $0.25(0.17-0.37)$ & $0.43(0.28-0.66)$ & $0.28(0.23-0.35)$ & $0.71(0.56-0.90)$ \\
\hline Parasite prevalence $500 \mathrm{~m}$ radius & $1.06(1.05-1.06)$ & $1.07(1.06-1.07)$ & $1.03(1.02-1.03)$ & \\
\hline Antibody prevalence $500 \mathrm{~m}$ radius & $1.02(1.02-1.03)$ & & $1.04(1.03-1.04)$ & $1.04(1.03-1.04)$ \\
\hline TWI (minimum) & & & $1.91(1.70-2.16)$ & $1.23(1.06-1.41)$ \\
\hline TWI (mean) & & & $2.16(1.94-2.41)$ & \\
\hline TWI (maximum) & $1.03(1.01-1.05)$ & $0.97(0.95-1.00)$ & $1.09(1.07-1.10)$ & \\
\hline
\end{tabular}

${ }^{a}$ Adjusted for clustering on compound level. The odds ratio and $95 \%$ confidence interval of household and geographical factors in relation to antibody prevalence, after adjustment for age and clustering of observations; TWI is topographical wetness index

water and the proportion of antibody or parasite positive individuals in the immediate vicinity of a compound were statistically significant and biologically plausible factors associated with malaria risk. The latter could suggest considerable between household transmission.

\section{Conclusions}

Evidence of relatively stable malaria transmission in this site at 1350-1600 m altitude was observed. Altitude was a major driver of malaria transmission in the study area, even across narrow altitude bands. Although malaria risk was spatially heterogeneous, the strong correlation between current parasite carriage and serological markers of malaria exposure and other established risk factors for malaria indicate temporal stability of geographical patterns in malaria exposure. The fine scale heterogeneity in this low-endemic setting may reflect a likely scenario for more endemic areas with active and effective control programmes as they reduce transmission to increasingly low levels. A priori knowledge of the factors that influence residual malaria in foci of low transmission is likely to further expedite control and elimination attempts.

\section{Authors' contributions}

$A B, J S, C D, J C$ and TB designed the field studies and AB, JS, GS, VO, CO and WO sample collection. AB, WS, VO, EM, PC and SS participated in the running of molecular and immunoassays. AB, JC, PK and TB worked on the collection of geographical information. $A B, J S, W O$ and GS performed database assembly and cleaning. $A B, J S, S K, C D, J C$ and $T B$ revised the manuscript. $T B, J C$ and $A B$ conceived the experiments, aided their design, and contributed to the drafting and revision of the manuscript. All authors read and approved the final manuscript.

\section{Author details}

${ }^{1}$ Department of Medical Microbiology, Radboud University Medical Centre, Geert Grooteplein 26-28, 6525, GA, Nijmegen, The Netherlands. ${ }^{2}$ European Programme for Public Health Microbiology Training, European Centre of Disease Prevention and Control (ECDC), Stockholm, Sweden. ${ }^{3}$ Department of Infectious and Tropical Diseases, London School of Hygiene and Tropical Medicine, Keppel Street, WC1E 7HT London, UK. ${ }^{4}$ Johns Hopkins Bloomberg 
School of Public Health, 615 North Wolfe Street, Baltimore, MD 21205, USA. ${ }^{5}$ Department of Mathematical Sciences, University of Bath, Claverton Down, Bath BA2 7AY, UK. ${ }^{6}$ Kenya Medical Research Institute, Mumias Road, Kisumu Station, Kisian, Kisumu, Kenya.

\section{Acknowledgements}

We thank all the project staff, the community of Kabondo and Kasipul, Rachuonyo South, and KEMRI/CDC Kisumu for their support. This manuscript has been approved by the Director of the Kenya Medical Research Institute.

\section{Competing interests}

The authors declare that they have no competing interests.

\section{Funding}

This work was supported by the Bill and Melinda Gates Foundation, under the Malaria Transmission Consortium, Grant No. 45114 and the Grand Challenge Grant No. OPP1024438. TB is further supported by a VIDI fellowship from the Netherlands Organization for Scientific Research (NWO; project number 016.158.306).

Received: 17 February 2016 Accepted: 27 May 2016

Published online: 04 June 2016

\section{References}

1. Woolhouse ME, Dye C, Etard JF, Smith T, Charlwood JD, Garnett GP, et al. Heterogeneities in the transmission of infectious agents: implications for the design of control programs. Proc Natl Acad Sci USA. 1997;94:338-42.

2. Bousema T, Griffin JT, Sauerwein RW, Smith DL, Churcher TS, Takken W, et al. Hitting hotspots: spatial targeting of malaria for control and elimination. PLoS Med. 2012;3(9):e1001165.

3. Hay SI, Snow RW. The malaria atlas project: developing global maps of malaria risk. PLoS Med. 2006;3:2204-8.

4. Hay SI, Guerra CA, Gething PW, Patil AP, Tatem AJ, Noor AM, et al. A world malaria map: Plasmodium falciparum endemicity in 2007. PLoS Med. 2009;6:e1000048.

5. Guerra CA, Gikandi PW, Tatem AJ, Noor AM, Smith DL, Hay SI, et al. The limits and intensity of Plasmodium falciparum transmission: implications for malaria control and elimination worldwide. PLoS Med. 2008;5:e38.

6. Oesterholt MJ, Bousema JT, Mwerinde OK, Harris C, Lushino P, Masokoto $A$, et al. Spatial and temporal variation in malaria transmission in a low endemicity area in northern Tanzania. Malar J. 2006;5:98.

7. Pruett-Jones SG, Pruett-jones MA, Jones HI. Parasites and sexual selection in birds of paradise. Integr Comp Biol. 1990;30:287-98.

8. Kreuels B, Kobbe R, Adjei S, Kreuzberg C, von Reden C, Bäter K, et al. Spatial variation of malaria incidence in young children from a geographically homogeneous area with high endemicity. J Infect Dis. 2008;197:85-93.

9. Bousema T, Drakeley C, Gesase S, Hashim R, Magesa S, Mosha F, et al. Identification of hot spots of malaria transmission for targeted malaria control. J Infect Dis. 2010;201:1764-74.

10. Carter R, Mendis KN, Roberts D. Spatial targeting of interventions against malaria. Bull World Health Organ. 2000;78:1401-11.

11. Ghebreyesus TA, Haile M, Witten KH, Getachew A, Yohannes AM, Yohannes M, et al. Incidence of malaria among children living near dams in northern Ethiopia: community based incidence survey. BMJ. 1999;319:663-6.

12. Zhou G, Munga S, Minakawa N, Githeko AK, Yan G. Spatial relationship between adult malaria vector abundance and environmental factors in western Kenya highlands. Am J Trop Med Hyg. 2007;77:29-35.

13. Ghebreyesus TA, Haile M, Witten KH, Getachew A, Yohannes M, Lindsay SW, et al. Household risk factors for malaria among children in the Ethiopian highlands. Trans R Soc Trop Med Hyg. 2000;94:17-21.

14. Gamage-Mendis AC, Carter R, Mendis C, De Zoysa AP, Herath PRJ, Mendis KN. Clustering of malaria infections within an endemic population: risk of malaria associated with the type of housing construction. Am J Trop Med Hyg. 1991;45:77-85.

15. Mackinnon MJ, Mwangi TW, Snow RW, Marsh K, Williams TN. Heritability of malaria in Africa. PLoS Med. 2005;2:e340.
16. Naidoo S, London L, Burdorf A, Naidoo RN, Kromhout H. Occupational activities associated with a reported history of malaria among women working in small-scale agriculture in South Africa. Am J Trop Med Hyg. 2011;85:805-10.

17. Shanks GD, Biomndo K, Guyatt HL, Snow RW. Travel as a risk factor for uncomplicated Plasmodium falciparum malaria in the highlands of western Kenya. Trans R Soc Trop Med Hyg. 2005;99:71-4.

18. Tusting LS, Bousema T, Smith DL, Drakeley C. Measuring changes in Plasmodium falciparum transmission. Precision, accuracy and costs of metrics. Adv Parasitol. 2014;84:151-208.

19. Bejon P, Williams TN, Nyundo C, Hay SI, Benz D, Gething PW, et al. A microepidemiological analysis of febrile malaria in coastal Kenya showing hotspots within hotspots. Elife. 2014;2014:e02130.

20. Bejon P, Williams TN, Liljander A, Noor AM, Wambua J, Ogada E, et al. Stable and unstable malaria hotspots in longitudinal cohort studies in Kenya. PLoS Med. 2010;7:e1000304.

21. John CC, Riedesel MA, Magak NG, Lindblade KA, Menge DM, Hodges JS, et al. Possible interruption of malaria transmission, highland Kenya, 2007-2008. Emerg Infect Dis. 2009;15:1917-24.

22. World Health Organization. Malaria early warning systems: concepts, indicators and partners - a framework for field research in Africa. WHO. CDS/RBM/2001.32. Geneva: World Health Organization; 2001.

23. Cox J, Hay SI, Abeku TA, Checchi F, Snow RW. The uncertain burden of Plasmodium falciparum epidemics in Africa. Trends Parasitol. 2007;23:142-8.

24. Hay SI, Noor AM, Simba M, Busolo M, Guyatt HL, Ochola SA, et al. Clinical epidemiology of malaria in the highlands of Western Kenya. Emerg Infect Dis. 2002;8:543-8.

25. Ernst KC, Adoka SO, Kowuor DO, Wilson ML, John CC. Malaria hotspot areas in a highland Kenya site are consistent in epidemic and non-epidemic years and are associated with ecological factors. Malar J. 2006;5:78.

26. Rolfes MA, McCarra M, Magak NG, Ernst KC, Dent AE, Lindblade KA, et al. Development of clinical immunity to malaria in highland areas of low and unstable transmission. Am J Trop Med Hyg. 2012;87:806-12.

27. Baliraine FN, Afrane YA, Amenya DA, Bonizzoni M, Menge DM, Zhou G, et al. High prevalence of asymptomatic Plasmodium falciparum infections in a highland area of western Kenya: a cohort study. J Infect Dis. 2009;200:66-74.

28. Stevenson J, St. Laurent B, Lobo NF, Cooke MK, Kahindi SC, Oriango $\mathrm{RM}$, et al. Novel vectors of malaria parasites in the western highlands of Kenya. Emerg Infect Dis. 2012;18:1547-9.

29. Bousema T, Stevenson J, Baidjoe A, Stresman G, Griffin JT, Kleinschmidt I, et al. The impact of hotspot-targeted interventions on malaria transmission: study protocol for a cluster-randomized controlled trial. Trials. 2013;14:36.

30. Corran P, Coleman P, Riley E, Drakeley C. Serology: a robust indicator of malaria transmission intensity? Trends Parasitol. 2007;23:575-82.

31. Baidjoe A, Stone W, Ploemen I, Shagari S, Grignard L, Osoti V, et al. Combined DNA extraction and antibody elution from filter papers for the assessment of malaria transmission intensity in epidemiological studies. Malar J. 2013;12:272.

32. Drakeley CJ, Corran PH, Coleman PG, Tongren JE, McDonald SLR, Carneiro I, et al. Estimating medium- and long-term trends in malaria transmission by using serological markers of malaria exposure. Proc Natl Acad Sci USA. 2005;102:5108-13.

33. Brown BL, Slaughter AD, Schreiber ME. Controls on roxarsone transport in agricultural watersheds. Appl Geochemistry. 2005;20:123-33.

34. Snounou G, Viriyakosol S, Zhu XP, Jarra W, Pinheiro L, Do Rosario VE, et al. High sensitivity of detection of human malaria parasites by the use of nested polymerase chain reaction. Mol Biochem Parasitol. 1993;61:315-20.

35. Cohen JM, Ernst KC, Lindblade KA, Vulule JM, John CC, Wilson ML. Local topographic wetness indices predict household malaria risk better than land-use and land-cover in the western Kenya highlands. Malar J. 2010;9:328.

36. Cook J, Kleinschmidt I, Schwabe C, Nseng G, Bousema T, Corran PH, et al. Serological markers suggest heterogeneity of effectiveness of malaria control interventions on Bioko Island equatorial guinea. PLoS One. 2011;6:e25137.

37. Bousema T, Stresman G, Baidjoe AY, Bradley J, Knight P, Stone W, et al. The impact of hotspot targeted interventions on malaria transmission in 
Rachuonyo South district in the western Kenyan Highlands: a clusterrandomized controlled trial. PLoS Med. 2016;13:e1001993.

38. Cook J, Speybroeck N, Sochantha T, Somony H, Sokny M, Claes F, et al. Sero-epidemiological evaluation of changes in Plasmodium falciparum and Plasmodium vivax transmission patterns over the rainy season in Cambodia. Malar J. 2012;11:86.

39. Shanks GD, Hay SI, Omumbo JA, Snow RW. Malaria in Kenya's western highlands. Emerg Infect Dis. 2005;11:1425-32.

40. Lindsay SW, Martens WJM. Malaria in the African highlands: past, present and future. Bull World Health Organ. 1998;76:33-45.

41. Okell LC, Bousema T, Griffin JT, Ouédraogo AL, Ghani AC, Drakeley CJ. Factors determining the occurrence of submicroscopic malaria infections and their relevance for control. Nat Commun. 2012;3:1237.
42. Chen I, Clarke SE, Gosling R, Hamainza B, Killeen G, Magill A, et al. "Asymptomatic" malaria: a chronic and debilitating infection that should be treated. PLoS Med. 2016;13:e1001942.

43. Buckee CO, Wesolowski A, Eagle NN, Hansen E, Snow RW. Mobile phones and malaria: modeling human and parasite travel. Travel Med Infect Dis. 2013;11:15-22.

44. Wesolowski A, Eagle N, Tatem AJ, Smith DL, Noor AM, Snow RW, et al. Quantifying the impact of human mobility on malaria. Science. 2012;338:267-70.

45. Kirby MJ, Ameh D, Bottomley C, Green C, Jawara M, Milligan PJ, et al. Effect of two different house screening interventions on exposure to malaria vectors and on anaemia in children in the Gambia: a randomised controlled trial. Lancet. 2009;374:998-1009.

46. Kirby MJ, West P, Green C, Jasseh M, Lindsay SW. Risk factors for houseentry by culicine mosquitoes in a rural town and satellite villages in The Gambia. Parasit Vectors. 2008;1:41.

\section{Submit your next manuscript to BioMed Central and we will help you at every step:}

- We accept pre-submission inquiries

- Our selector tool helps you to find the most relevant journal

- We provide round the clock customer support

- Convenient online submission

- Thorough peer review

- Inclusion in PubMed and all major indexing services

- Maximum visibility for your research

Submit your manuscript at www.biomedcentral com/submit
() Biomed Central 